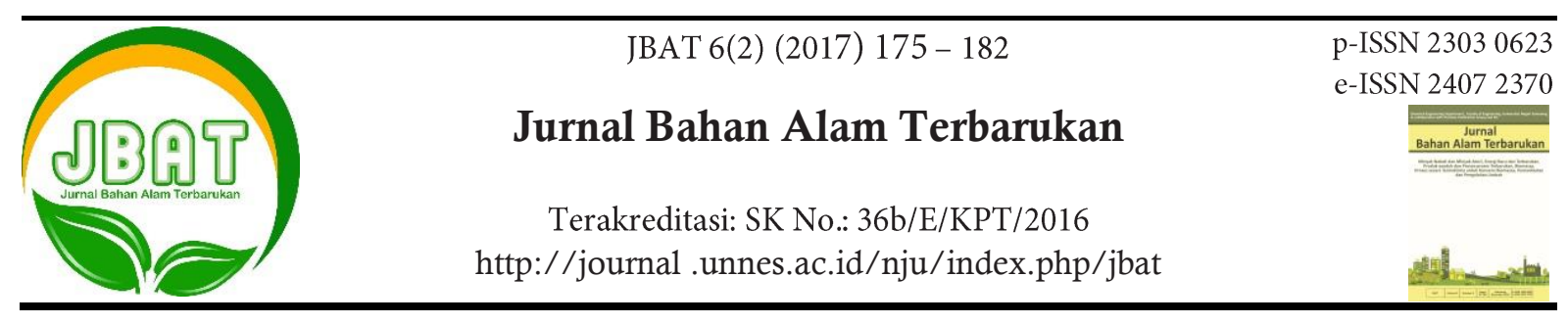

\title{
Glyptal Synthesis from Glycerol and Phthalic Anhydride Using Activated Zeolite as Heterogeneous Catalyst and Its Comparison to Homogeneous $p$-Toluenesulfonic Acid Catalyst
}

\author{
Budhijanto $^{\bowtie}$, Deddy Wirata, Kurniawan
}

DOI 10.15294/jbat.v6i2.12065

Chemical Product Technology and System Engineering Group, Chemical Engineering Department Faculty of Engineering Universitas Gadjah Mada, J1. Grafika 2 Yogyakarta 55281

\begin{tabular}{l} 
Article Info \\
\hline Article history: \\
Received \\
$\quad$ November 2017 \\
Accepted \\
$\quad$ December 2017 \\
Published \\
$\quad$ December 2017 \\
\hline Keywords : \\
Glyptal; \\
Glycerol, \\
polyesterification; \\
polyester; \\
Activated zeolite; \\
p-toluenesulfonic \\
acid; \\
Homogeneous \\
catalyst; \\
Heterogeneous \\
catalyst \\
\hline
\end{tabular}

\begin{abstract}
The abundance of glycerol as the side product of biodiesel has motivated researches on glycerol utilization as a feedstock for more valuable products. This research presents the possibility of producing polyester (glyptal), which is a widely used coating material, from glycerol by esterification using phthalic anhydride. Esterification reaction of phthalic anhydride and glycerol to produce glyptal can be catalyzed by Lewis acid provided by either homogeneous or heterogeneous catalyst. This study compared the performance of activated zeolite as heterogeneous catalyst in the esterification of glycerol and phthalic anhydride with the performance of $p$-toluenesulfonic acid (PTSA) as homogeneous catalyst. The reactions were carried out in laboratory scale batch reactor. The kinetics was modeled using Step Growth Polymerization Model. The rate constant obtained from experimental data fitting on the model was correlated with temperature by Arrhenius equation. Both activated zeolite and PTSA exhibited Arrhenius behavior. Based on the comparison of the Arrhenius constants of the reaction catalyzed by each of the two different catalysts, PTSA performed better in term of lower activation energy. Nevertheless, this result did not suggest that activated zeolite was failed. The activated zeolite was successful to make the reaction happen. To reach the same performance as the homogeneous PTSA, the activated zeolite needs to be improved with respect to its cation exchange capacity and also the operational consideration such as the amount of zeolite added per volume of reaction and the intensity of mixing to minimize the diffusion resistance surrounding the zeolite particles.
\end{abstract}

\section{INTRODUCTION}

The trend of increasing biodiesel production in Indonesia, from 413,000 tons in 2009 to 2.58 million tons in 2014 (EBTKE, 2014; Amin, 2014), has also increased the emission of glycerol as the side product in biodiesel production through transesterification of triglycerides. While its abundance makes glycerol considered having low economic value, it is actually an intermediate compound to produce various products with higher price. The possible high-valued product of glycerol can even improve the profitability of biodiesel production as renewable fuel, whose production cost is currently still considered high especially in developing countries (Miran et al., 2017).

One of possible utilization of glycerol is in the production of polyesters (Bueno et al., 2015; Valario et al., 2015), which are highly demanded as a widespread variety of products such as textile and coating agents (Miran et al., 2017; Velayutham et al., 2009; Alam et al., 2014). Coating agents derived from natural resources such as vegetable oil are currently preferable because of the environmentally benign production process and their least effect on health in application (Alam et al., 2014; Sharmin et

(C) 2017 Semarang State University

\footnotetext{
${ }^{\square}$ Corresponding author:

Chemical Product Technology and System Engineering Group

Chemical Engineering Department Faculty of Engineering Universitas Gadjah Mada

E-mail: budhijanto@ugm.ac.id
}

ISSN 2303-0623 


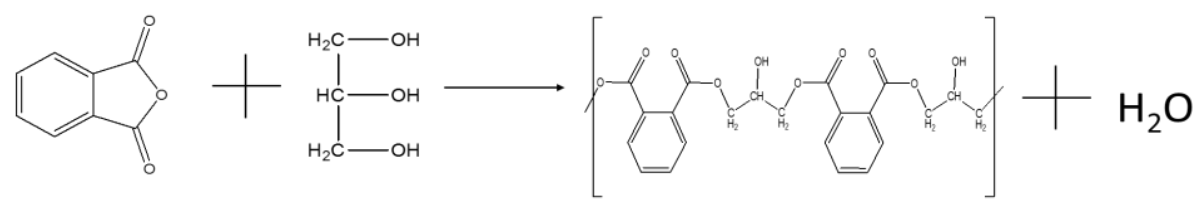

Table 1. Stoichiometric balance of the reaction of phthalic anhydride and glycerol

\begin{tabular}{lllllll}
\hline Reaction: & $\mathbf{C O O H}$ & + & $\begin{array}{l}\text { OH } \\
(\mathrm{B})\end{array}$ & $---->$ & $\begin{array}{l}\text { COO- } \\
(\mathrm{C})\end{array}$ & $\begin{array}{l}\mathbf{H}_{2} \mathbf{O} \\
(\mathrm{W})\end{array}$ \\
\hline Initial moles & $\mathrm{C}_{\mathrm{A} 0}$ & & $1.5 \mathrm{C}_{\mathrm{A} 0}$ & - & - \\
Reacted moles & $-\Delta$ & & $-\Delta$ & $\Delta$ & $\Delta$ \\
Final moles & $\mathrm{C}_{\mathrm{A}}$ & & $1.5 \mathrm{C}_{\mathrm{A} 0-\Delta}$ & $\Delta$ & $\Delta$ \\
\hline
\end{tabular}

al., 2015). Reaction with phthalic anhydride converts glycerol into cross-linked polyester called glyptal, which is commonly used as thermosetting coating (Deligny \& Tuck, 2001). The resistance to elevated temperature makes glyptal suitable for coating material, especially for application in quite severe environment.

Polymerization reaction of glycerol and phthalic anhydride is represented by Eq. (1).

In the water, the phthalic anhydride will be readily hydrolyzed into phthalic acid, which has two carboxylic groups (-COOH). The kinetic study on the reaction represented as Eq. (1) was based on the concentrations of the carboxylic groups of the phthalic anhydride and the hydroxyl groups $(-\mathrm{OH})$ of the glycerol. Each carboxylic group will react with one hydroxyl group to form ester (Solomon \& Fryhle, 2011). With 1:1 mole ratio of phthalic anhydride and glycerol, the stoichiometry of the reaction is described in Table 1.

Based on Eq. (1) and mole balance in Table 1 , the concentrations of species involved in the esterification reaction are interconnected by Eq. 2 and Eq. 3.

$$
\begin{gathered}
C_{B}=0.5 C_{A 0}+C_{A} \\
C_{c}=C_{w}=C_{A 0}-C_{A}
\end{gathered}
$$

with $\mathrm{C}_{\mathrm{A} 0}=$ initial concentration of $\mathrm{COOH}$ ( $\left.\mathrm{mmol} / \mathrm{g}_{\text {solution}}\right), \mathrm{C}_{\mathrm{A}}=$ concentration of $\mathrm{COOH}$ at a particular time $\left(\mathrm{mmol} / \mathrm{g}_{\text {solution }}\right), \mathrm{C}_{\mathrm{B}}=$ concentration of $\mathrm{OH}$ at a particular time $\left(\mathrm{mmol} / \mathrm{g}_{\text {solution }}\right), \mathrm{C}_{\mathrm{C}}=$ concentration of ester at a particular time ( $\mathrm{mmol} / \mathrm{g}_{\text {solution}}$ ), and $\mathrm{C}_{\mathrm{W}}=$ concentration of water formed at a particular time $\left(\mathrm{mmol} / \mathrm{g}_{\text {solution}}\right)$.

The reaction rate was modeled using Step Growth Polymerization model. This model assumed that the reaction between - $\mathrm{COOH}$ and $-\mathrm{OH}$ to form ester bond proceeded mostly through the interactions of reactants. Therefore the reaction was assumed to be first order reaction with respect to each reactant (Fogler, 2006), which were $\mathrm{COOH}$ $\left(\mathrm{C}_{\mathrm{A}}\right)$ and $\mathrm{OH}\left(\mathrm{C}_{\mathrm{B}}\right)$. The rate of reaction of $\mathrm{A}\left(-r_{A}\right)$ was expressed in Eq. 4.

$$
\left(-r_{A}\right)=k C_{A} C_{B}
$$

where $k=$ the reaction rate constant $\left(\mathrm{g}_{\text {solution }} \mathrm{mmol}^{-1}\right.$ $\left.\min ^{-1}\right)$. By taking into account the mole balance in Eq. (2) and by means of integration, the correlation between $\mathrm{C}_{\mathrm{A}}$ and reaction time ( $\mathrm{t}$, in minutes) is obtained as Eq. 5.

$$
-\frac{2}{C_{A 0}}\left[\ln \left(\frac{C_{A}}{C_{A 0}}\right)-\ln \left(\frac{C_{A 0}+2 C_{A}}{3 C_{A 0}}\right)\right]=k t
$$

As other esterification reaction, in order for the reaction (Eq. 1) to happen, Lewis acid is needed to provide catalysis effect (Solomon \& Fryhle, 2011). There is currently a trend to seek for more environmentally benign processes, which is widely acknowledged as "green chemistry". One of the fundamental concept in green chemistry is preventing the emission of waste and avoiding the use of toxic materials (Gupta \& Paul, 2014).

With respect to the effort to comply with green chemistry philosophy, the choice of catalyst is very important to ensure the cleaner production method. Acid catalyst is by far the most used catalyst in industrial sector. Inorganic or mineral acids are still the main choice in industry. Although it is undoubtedly facilitating the reaction to proceed very well, some drawbacks are identified for mineral acids usage, such as high toxicity, problem in product purification, and usually environmentally undesirable (Gupta \& Paul, 2014).

The alternative to reduce the use of mineral acids is the application of solid acid catalyst, such as silica based solid acids (Gupta \& Paul, 2014). The advantage of silica based catalyst is the fact that 


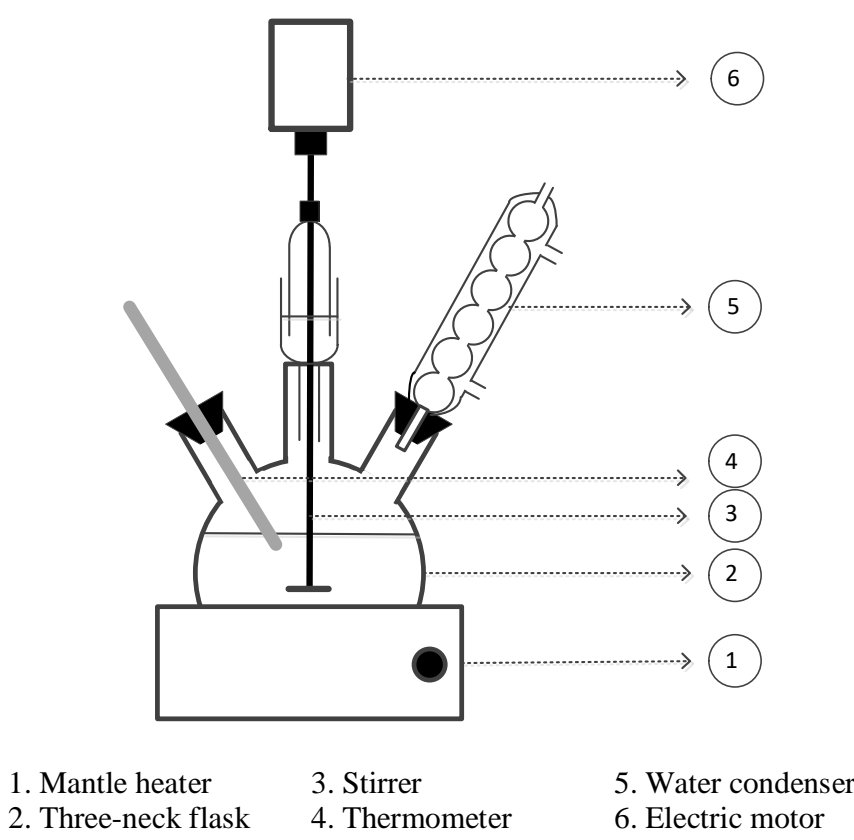

Figure 1. Experimental set up

this type of catalyst is widely available and inexpensive, high porosity, and easily functionalized to serve a particular reaction. Indonesia is rich of natural zeolite as the source of silica based catalyst. Upon activation using appropriate agents, activated zeolite can serve a wide range of reaction, including esterification (Bedard et al., 2012; Yue et al., 2016; Doyle et al., 2016).

In this preliminary study of glyptal production, the performance of solid/heterogeneous catalyst is compared to liquid/homogeneous catalyst. Activated zeolite was chosen as the heterogeneous catalyst (Kurniawan, 2017), while $p$-toluenesulfonic acid (PTSA) was taken as the homogeneous catalyst (Wirata, 2017; Fernandes et al., 2012). The rate constant $\mathrm{k}$ in Eq. 5 was determined for each set of time-concentrations data obtained at each temperature. To compare the performance of two different catalysts, the values of $\mathrm{k}$ and temperatures were correlated using the Arrhenius equation, as shown by Eq. 6, to obtain the pre-exponential constant $\mathrm{A}$ ( $\mathrm{g}_{\text {solution }} \mathrm{mmol}^{-1} \mathrm{~min}$ $\left.{ }^{1}\right)$ and activation energy constant $\mathrm{E}(\mathrm{cal} / \mathrm{mol})$.

$$
\ln k=\ln A-\frac{E}{R}\left(\frac{1}{T}\right)
$$

Here, $R=$ ideal gas constant $\left(=1.987 \mathrm{cal} \mathrm{mol}^{-1} \mathrm{~K}^{-1}\right)$ and $T=$ temperature of reaction $(\mathrm{K})$.

The comparison of the performance of the heterogeneous and homogeneous catalysts was then conducted based on the Arrhenius constants.

\section{RESEARCH METHODOLOGY}

\section{Materials}

One of the reactants, technical grade glycerol $(98,65 \%$ purity) was supplied by CV. Bratachem Yogyakarta, Indonesia. Phthalic anhydride (p.a., $\geq 98.0 \%$ purity) from Merck was used as the other reactant. Natural zeolite of clinoptilolite type was obtained from Klaten Regency, Indonesia. The natural zeolite was activated using hydrochloric acid (p.a 37\% purity) from Merck diluted with aquadest to the concentration of $6 \mathrm{~N}$. As a comparison to the activated zeolite, PTSA (p.a. $\geq 98.0 \%$ purity) from Merck was used as a homogeneous catalyst.

\section{Experimental set up}

The experiments were carried out in a laboratory scale batch stirred reactor equipped with mantle heater and condenser (Figure 1).

Glycerol as much as $71 \mathrm{~mL}$ was put in the reactor and heated to the desired temperatures, which were 393, 403, 413, 423, and $433 \mathrm{~K}$. After reaching the targeted temperature, $140.3 \mathrm{~g}$ of phthalic anhydride was introduced into the reactor and stirred until completely dissolved in glycerol. Catalyst was added when the reactants had been perfectly dissolved.

Experiments were conducted in two schemes of reactor operations. The first scheme used activated zeolite as the heterogeneous catalyst, 
while in the second scheme, PTSA was used as the homogeneous catalyst. Natural zeolite was activated by adding $50 \mathrm{~g}$ of natural zeolite into 250 $\mathrm{mL}$ of $6 \mathrm{~N}$ hydrochloric acid in a closed flask equipped with stirrer. The mixture was stirred at $393 \mathrm{~K}$ for 2 hours. The activated zeolite was washed by aquadest prior to its usage as the catalyst in the aforementioned reactor. Samples were taken from the glyptal reactor every 30 minutes. The $-\mathrm{COOH}$ content of the sample was determined using titration with standardized $1 \mathrm{~N} \mathrm{KOH}$ solution.

The second scheme used the same amount of glycerol and phthalic anhydride. The difference was the usage of PTSA as homogeneous catalyst. As much as 1.1 gram of PTSA $(0.5 \% \mathrm{w} / \mathrm{w}$ of the total reaction mixture) was added into the reaction mixture. The temperature variation experiments were then conducted in the same manner as described previously for the heterogeneous catalyst scheme.

\section{Data analysis}

Comparison between the reaction performance while using activated zeolite and PTSA was conducted by comparing the values of the rate constants in the Step Growth Polymerization model. The rate constants for each set of data were determined using linear regression based on Eq. 5 . The linearity of Eq. 5 can be shown by defining a new variable, $Y$, as follows.

$$
Y=-\frac{2}{C_{A 0}}\left[\ln \left(\frac{C_{A}}{C_{A 0}}\right)-\ln \left(\frac{C_{A 0}+2 C_{A}}{3 C_{A 0}}\right)\right]
$$

Thus, for every value of $C_{A}$, we can calculate $Y$. As a result, we have a set data of $Y$ vs $t$, whose linearity is representing by Eq. 8 .

$$
Y=k t
$$

The linear regression method numerically searched for the rate constant value $k$ which gave the calculated $C_{A}$ as close as the experimental values. Thus, the uncertainty of the experimental results is represented by the average error (AE) as follows.

$$
A E=\frac{\sum_{i=1}^{N} \frac{\left|C_{\text {Acalc }, i}-C_{\text {Aexp }, i}\right|}{C_{\text {Acalc. }, i}}}{N} \times 100 \%
$$

Here, $C_{\text {Acalc. }, i}=$ concentration of $\mathrm{COOH}$ calculated using Eq. 5 at a certain time $t$ with $k$ obtained from the linear regression computation $\left(\mathrm{mmol} / \mathrm{g}_{\text {solution }}\right), C_{\text {Aexp.i }}=$ experimental value of concentration of $\mathrm{COOH}$ at a certain time $t$ ( $\left.\mathrm{mmol} / \mathrm{g}_{\text {solution }}\right)$, and $N=$ the number of datum points. To get better information on how far the reaction has progressed, conversion of $\mathrm{COOH}, X_{A}$, is calculated using Eq. 10.

$$
X_{A}=\frac{C_{A 0}-C_{A}}{C_{A 0}}
$$

Furthermore, the rate constants $k$ from experiments with different temperatures were fit in Arrhenius Equation to obtain the expression for temperature effect. The values of constants in Arrhenius Equation were determined using linear regression of rate constant $(\ln k)$ and temperature $(1 / T)$ data according to Eq. 6 .

\section{RESULTS AND DISCUSSIONS}

\section{Activated Zeolite as Heterogeneous Catalyst}

Figure 2 shows that with activated zeolite, esterification took place at all temperatures tested. Elevated temperature was preferred for larger extent of reaction, as the reaction rate was significantly affected by temperature. To obtain deeper insight of the temperature effect, the data in Figure 2 were fitted into Eq. 5 combined with Eq. 7 to 10 to calculate the rate constant (k) using linear regression. The resulted $\mathrm{k}$ values are presented numerically in Table 2 and plotted with temperature variation as Figure 3.

Figure 2 shows that the Step Growth Polymerization model works well on the experimental data of the reaction using activated zeolite as the heterogeneous catalyst. The relatively low average errors which are less than $5 \%$ prove that the kinetic model succesfully described the progress of the reaction. Figure 3 confirms that the rate constant follows the Arrhenius model very well.

\section{Para Toluene Sulfonic Acid as Homogeneous Catalyst}

The same kinetics analysis was conducted for the experiments using PTSA as homogeneous catalyst. The plot of $\mathrm{COOH}$ conversion with time at 


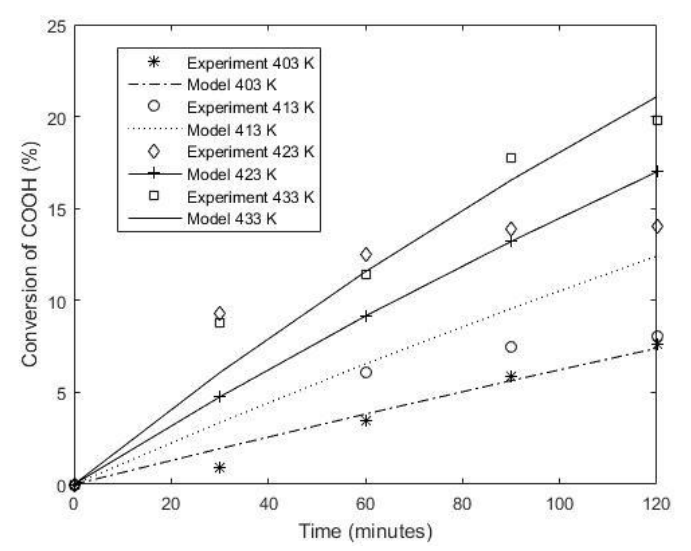

Figure 2. Conversion profile of $-\mathrm{COOH}$ for reaction using activated zeolite catalyst

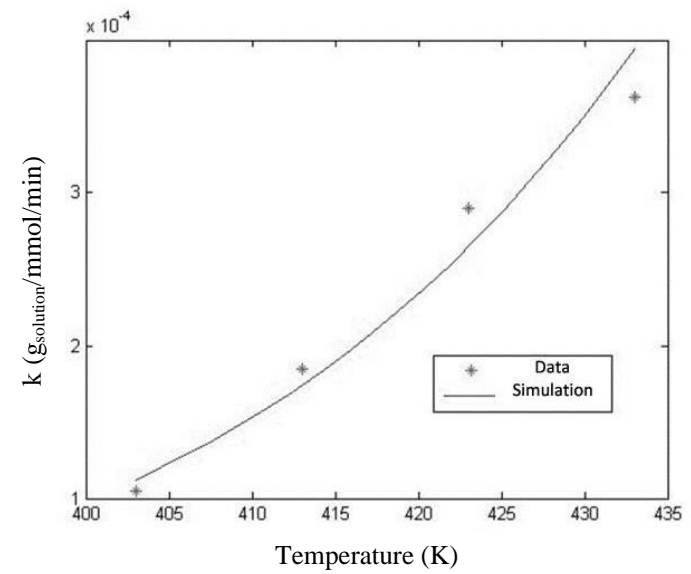

Figure 3. Effect of temperature on the rate constant in Step Growth Polymerization model when activated zeolite was used as heterogeneous catalyst

Table 2. Values of rate constant (k) in Step Growth Polymerization model for reaction using activated zeolite catalyst

\begin{tabular}{ccc}
\hline Temperature, $\mathrm{K}$ & $\mathrm{k} \mathrm{x} 10^{4}, \mathrm{~g}_{\text {solution }} \mathrm{mmol}^{-1} \mathrm{~min}^{-1}$ & Average errors $\%$ \\
\hline 403 & 1.0458 & 0.40 \\
413 & 1.8483 & 1.37 \\
423 & 2.8968 & 1.94 \\
433 & 3.6310 & 1.24 \\
\hline
\end{tabular}

various temperatures is presented in Figure 4. The list of rate constants at various temperatures is presented in Table 3. In the range of tested temperature (393-433 K), the effect of temperature is equally significant.

Figure 4 and 5 show that the Step Growth Polymerization model also works well on the experimental data of the reaction using PTSA as the homogeneous catalyst. The low average errors which are less than $5 \%$ prove that the kinetic model successfully captured the trend of the data.

\section{Comparison between the performance of activated zeolite and PTSA}

Figure 3 and Figure 5 confirm that both reactions with activated zeolite or PTSA as catalyst demonstrate Arrhenius behavior. Table 4 presents the values of Arrhenius constants for both the reaction catalyzed by activated zeolite and by PTSA. Table 4 shows that activated zeolite and PTSA as catalysts incur difference in both the preexponential constant of Arrhenius equation (A) and the energy activation constant $(\mathrm{E})$.

However, the difference in the catalytic activity of zeolite and PTSA is more dominantly caused by the pre-exponential constant, which implies the number of collisions with correct orientation for the reaction to occur. A speculative explanation inferred from the pre-exponential difference is the possibility of the difference in the amount of transferrable $\mathrm{H}^{+}$from the activated zeolite and the PTSA used in the experiments. In this preliminary research, the amount of transferrable $\mathrm{H}^{+}$of both types of catalyst was not carefully measured to ensure the same catalytic potential. The importance of the amount of transferrable $\mathrm{H}^{+}$from the catalyst in this type of reaction was observed in other researches (Liu et al, 2006a; Liu et al., 2006b).

While the pre-exponential constant reflects the number of collision with correct orientation to enable reaction, it should be noted that the actual reaction can only take place when the reacting molecules have sufficient energy to exceed the minimum activation energy for the reaction to happen. For every reaction, there is an energy barrier that hinders the reaction to occur. This energy barrier is basically the difference between the energy of the reactants and the energy of the transition state. This energy barrier that is called activation energy can not be directly measured; instead it must be calculated from the experimental data (Solomon \& Fryhle, 2011). 


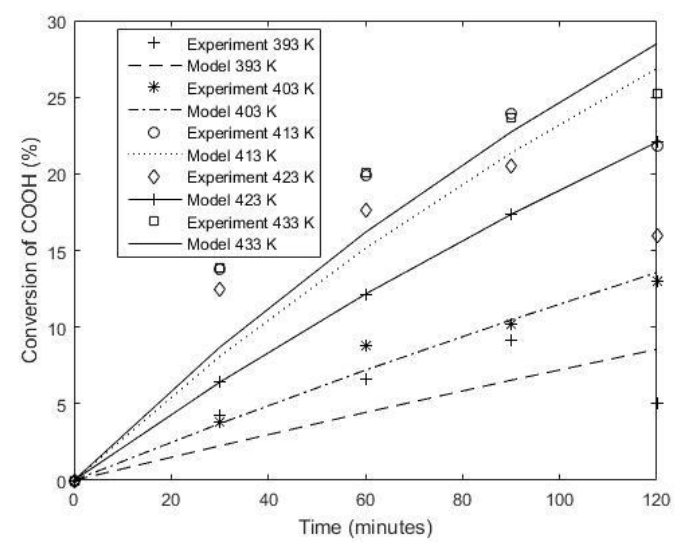

Figure 4. Conversion profile of $-\mathrm{COOH}$ for reaction using PTSA as homogenenous catalyst

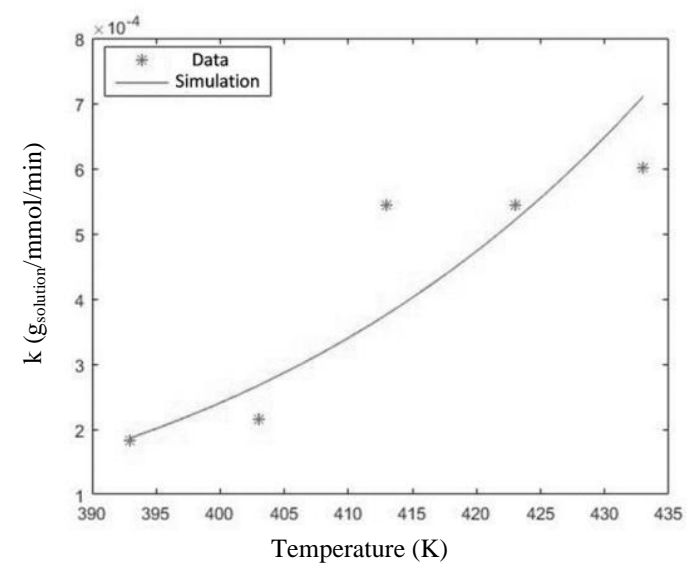

Figure 5. Effect of temperature on the rate constant in Step Growth Polymerization model when PTSA was used as homogeneous catalyst

Table 3. Values of rate constant (k) in Step Growth Polymerization model for reaction using PTSA (1:1 mol ratio to glycerol)

\begin{tabular}{ccc}
\hline Temperature, $\mathrm{K}$ & $\mathrm{k} \mathrm{x} 10^{4}, \mathrm{~g}_{\text {solution }} \mathrm{mmol}^{-1} \mathrm{~min}^{-1}$ & Average errors, $\%$ \\
\hline 393 & 1,8245 & 0.34 \\
403 & 2.1483 & 0.55 \\
413 & 5.4260 & 2.09 \\
423 & 5.4433 & 2.19 \\
433 & 6.0092 & 2.25 \\
\hline
\end{tabular}

Table 4. Comparison of Arrhenius constants for glyptal formation from glycerol and phthalic anhydride using zeolite and PTSA catalysts

\begin{tabular}{lccc}
\hline \multirow{2}{*}{ Arrhenius constants } & \multicolumn{2}{c}{ Catalyst } \\
\cline { 2 - 4 } & Activated zeolite & PTSA \\
\hline Pre-exponent constant & $(\mathrm{A})$, & $8,719.9$ & 358.1 \\
gsolutionmmol $^{-1} \mathrm{~min}^{-1}$ & & \\
Activation energy (E), cal/mol & 14,550 & 11,297 \\
\hline
\end{tabular}

The activation energy, as shown in Table 4 , is the minimum energy required by every molecules collision in order to the reaction occurs successfully. Thus, only molecule collisions with energy exceeds the activation energy will produce the products. Table 4 shows that the energy activation (E) in the reaction catalyzed activated zeolite is higher than the energy activation of the PTSA catalyzed reaction. In other words, the barrier is higher in the activated zeolite catalyzed reaction. It is a logical consequence of the complication of the molecular mechanism in the activated zeolite catalyzed reaction, in which the bulky molecules of phthalic acid and glycerol have to overcome the diffusion resistance of the liquid to get close enough to the zeolite surface to get sufficient $\mathrm{H}^{+}$. Diffusion resistance was not a big issue in PTSA catalysis case as dissolved PTSA diffuses much more easily in a homogeneous phase with the reactants. The importance effect of diffusion in heterogenous catalytic reactions was also observed by several researchers (Bedard et al., 2012; Milina et al., 2014; Soltani et al., 2017).

The aforementioned comparison between activated zeolite and PTSA highlights the potential of activated zeolite to be preferably used in esterification reaction of glyptal production from phthalic anhydride and glycerol. Although the Arrhenius parameters in Table 4 suggests that PTSA catalyst performed better than the activated zeolite, it needs to be underlined that the importance of the results in this preliminary study is the confirmation that activated zeolite can potentially serve as the catalyst in glyptal 
production. Further study needs to be conducted especially with accurate measurement of the $\mathrm{H}^{+}$ sufficiency in the zeolite to achieve the same performance as the homogeneous catalyst.

\section{CONCLUSION}

Kinetics study on the performance of heterogeneous and homogeneous catalysts for the formation of glyptal from glycerol and phthalic anhydride raised important considerations for reactor design as the following:

a. With respect to- $\mathrm{COOH}$ conversion rate, PTSA as homogeneous catalyst performed better than the activated zeolite used as heterogeneous catalyst.

b. From economic point of view, solid catalyst is usually preferable for easier handling and possibility for repeated use when regeneration cycle is applied. This preliminary research confirmed the potential of zeolite as heterogeneous catalyst in glyptal production. In order to improve the performance of activated zeolite, further study is needed especially in the exploration of the optimum amount and mixing technique in the reactor to facilitate better mass transfer.

\section{REFERENCES}

D. EBTKE. 2014. Statistik EBTKE 2014. 1-110.

Amin, M.M. 2014. Studi potensi bisnis dan pelaku utama industri biodiesel di Indonesia. Available: www.edmione.com. [Accessed: 08-Aug-2016].

Miran, F., Mumtaz, M. W., Mukhtar, H., Danish, M. 2017. Value-added use of residual glycerol from biodiesel production process via the optimized synthesis of alkyd resins. Process Safety and Environmental Protection. 109:659-669.

Bueno, L., Toro, C., Martin, M. 2015. Technoeconomic evaluation of the production of polyesters from glycerol and adipic acid. Chemical Engineering Research and Design. 93:432-440.

Valerio, O., Horvath, T., Pond, C., Misra, M., Mohanty, A. 2015. Improved utilization of crude glycerol from biodiesel industries: Synthesis and characterization of sustainable biobased polyesters. Industrial Crops and Products. 78:141-147.
Velayutham, T. S., Majid, W. H. A., Ahmad, a. B., Kang, G. Y., Gan, S. N. 2009. Synthesis and characterization of polyurethane coatings derived from polyols synthesized with glycerol, phthalic anhydride and oleic acid. Progress in Organic Coatings. 66(4):367-371.

Alam, M., Akram, D., Sharmin, E., Zafar, F., Ahmad, S. 2014. Vegetable oil based ecofriendly coating materials: A review article. Arabian Journal of Chemistry. 7(4):469479.

Sharmin, E., Zafar, F., Akram, D. , Alam, M., Ahmad, S. 2001. Recent advances in vegetable oils based environment friendly coatings: A review. Industrial Crops and Products.76:215-229.

Deligny, P., Tuck, N. 2001. Resins for Surface Coatings: Alkyds and Polyesters. London: John Wiley \& Sons, Inc.

Solomon, T. W., Fryhle, C. B. 2011. Organic Chemistry. $10^{\text {th }}$ ed. New York: John Wiley \& Sons, Inc.

Fogler, H. S. 2006. Elements of Chemical Reaction Engineering. $4^{\text {th }}$ ed. New York: Pearson Education, Inc.

Gupta, P., Paul, S. 2014. Solid acids: Green alternatives for acid catalysis. Catalysis Today. 236(PART B):153-170.

Bedard, J., Chiang, H., Bhan, A. 2012. Kinetics and mechanism of acetic acid esterification with ethanol on zeolites. Journal of Catalysis. 290:210-219.

Yue, Y., Liu, H., Zhou, Y., Bai, Z., Bao, X. 2016. Pure-phase zeolite beta synthesized from natural aluminosilicate minerals and its catalytic application for esterification. Applied Clay Science. 126:1-6.

Doyle, A. M., Albayati, T. M., Abbas, A. S., Alismaeel, Z. T. 2016. Biodiesel production by esterification of oleic acid over zeolite Y prepared from kaolin. Renewable Energy. 97:19-23.

Kurniawan, K. 2017. Studi Kinetika Reaksi Polimerisasi dari Gliserol dan Phthalic Anhydride Menggunakan Katalis Zeolite Alam. Yogyakarta.

Wirata, D. 2017 .Studi kinetika reaksi gliserol dan phtalic anhydride dengan katalis para toluen sulfonic acid. Yogyakarta.

Fernandes, S. A., Natalino, R., Da Silva, M. J., Lima, C. F. 2012. A comparative 
investigation of palmitic acid esterification over p-sulfonic acid calix[4]arene and sulfuric acid catalysts via $1 \mathrm{H}$ NMR spectroscopy. Catalyst Communication. 26:127-131.

Liu, Y., Lotero, E., Goodwin, J. G. 2006a. A comparison of the esterification of acetic acid with methanol using heterogeneous versus homogeneous acid catalysis. Journal of Catalysis. 242(2):278-286.

Liu, Y., Lotero, E., Goodwin, J. G. 2006b. Effect of water on sulfuric acid catalyzed esterification. Journal of Molecular Catalysis A: Chemical. 245(1-2):132-140.

Milina, M., Mitchell, S., Pérez-Ramírez, J. 2014. Prospectives for bio-oil upgrading via esterification over zeolite catalysts. Catalyst Today. 235:176-183.

Soltani, S., Rashid, U., Al-Resayes, S. I., Nehdi, I. A. 2017. Recent progress in synthesis and surface functionalization of mesoporous acidic heterogeneous catalysts for esterification of free fatty acid feedstocks: A review. Energy Conversion and Management. 141:183-205. 